\title{
O Brasil homossexual em retrato: articulações entre direitos humanos, literatura e arte
}

\author{
Fabio Scorsolini-Comin ${ }^{1}$ \\ Universidade Federal do Triângulo Mineiro, Uberaba-MG, Brasil
}

Costa, H., Bento, B., Garcia, W., Inácio, E., \& Peres, W. S. (Orgs.). (2010). Retratos do Brasil homossexual: Fronteiras, subjetividades e desejos. São Paulo: Ed. USP/Imprensa Oficial.

Segundo resultados preliminares do Censo Demográfico 2010 do Instituto Brasileiro de Geografia e Estatística (IBGE), 60.002 brasileiros dizem morar com cônjuge do mesmo sexo. O número corresponde a $0,03 \%$ do total da população, ou três pessoas a cada grupo de 10 mil. Comparativamente, 19,7\% dos brasileiros afirmam morar com cônjuge de sexo diferente. Foi a primeira vez que o Censo incluiu a informação sobre parceiros do mesmo sexo na pesquisa (IBGE, 2011).

Outro fato inédito em nosso país ocorreu em maio de maio de 2011, em que o Supremo Tribunal Federal (STF) reconheceu as uniões estáveis de casais homossexuais. Na prática, isso significa que esses ministros entenderam que casais gays devem desfrutar de direitos semelhantes aos de pares heterossexuais, como pensões, aposentadorias e inclusão em planos de saúde. No dia 28 de junho de 2011, considerado o dia Internacional do Orgulho Gay e da Consciência Homossexual, ocorreu o primeiro casamento homoafetivo do Brasil, na cidade de Jacareí, estado de São Paulo.

Em julho de 2011, o jornal Estado de São Paulo anunciou que um casal gay de uma cidade do interior do Estado de São Paulo conseguiu adotar cinco irmãos com idades entre 4 e 10 anos. As crianças viviam em um abrigo público de uma cidade do interior do Estado do Rio de Janeiro. A justiça local trocou informações com a da cidade paulista para avaliar se o casal tinha condições de manter as crianças. O casal foi considerado apto e as crianças receberam os sobrenomes do casal adotante (Tomazela, 2011).

Tais acontecimentos recentes refletem não apenas uma mudança social, mas também demográfica, ampliando para outras dimensões as reflexões em torno dos arranjos familiares, hétero ou homoafetivos, o que aproxima a questão das políticas públicas (Prado \& Machado, 2008). É neste sentido que a obra Retratos do Brasil homossexual: Fronteiras,

\footnotetext{
${ }^{1}$ Endereço para correspondência:

Fabio Scorsolini-Comin. Universidade Federal do Triângulo Mineiro. Instituto de Educação, Letras, Artes, Ciências Humanas e Sociais. Departamento de Psicologia do Desenvolvimento, Educação e Trabalho. Avenida Getúlio Guaritá, 159. CEP 38.025-440. Uberaba-MG, Brasil. E-mail: scorsolini_usp@yahoo.com.br
}

subjetividades e desejos, organizada por Horácio Costa e colaboradores, constitui um marco nos estudos sobre o movimento homossexual no contexto nacional. Os capítulos que compõem o livro foram apresentados originalmente no IV Congresso da Associação Brasileira de Estudos da Homocultura (ABEH), ocorrido no ano de 2008 e estão divididos em cinco partes.

A parte I, intitulada Homocultura e direitos humanos, é composta por sete estudos que tratam de questões jurídicas relacionadas ao movimento homossexual, retomando concepções presentes em documentos legais, como na Constituição Federal de 1988. O capítulo de Maria Berenice Dias discorre que a Constituição em vigor foi considerada um avanço no sentido de legitimar outros arranjos familiares, como as uniões estáveis (ou seja, sem que haja o matrimônio) e as famílias monoparentais, ainda que se conserve o caráter tradicional, incentivando que essas uniões estáveis, por exemplo, transformem-se em casamentos. A autora destaca que o não reconhecimento das uniões entre pessoas do mesmo sexo neste documento fere o princípio da igualdade apregoado em documentos internacionais dos quais o Brasil é signatário, como o Pacto dos Direitos Civis e Políticos da ONU. Entre esses capítulos iniciais, destaca-se o de João Silvério Trevisan, considerado um dos pioneiros do movimento homossexual no Brasil. Ao resgatar a história da constituição desse movimento, faz reflexões no sentido de lançar perspectivas tanto para as pessoas diretamente envolvidas nesses movimentos sociais como para os estudos científicos na área. Afirma, por exemplo, que o movimento LGBTT (Lésbicas, Gays, Bissexuais, Transexuais e Transgêneros), no início da década de 1990, foi constituído a partir de uma contradição: de um lado, lutava-se pela visibilidade do movimento; de outro, castravam-se potenciais expressões individuais na própria militância homossexual.

A parte II é intitulada Homocultura e Literatura e compreende nove capítulos que discorrem sobre como o movimento homossexual tem sido retratado na literatura nacional e internacional. Destaca-se, por exemplo, as representações de gênero e de homoerotismo na Literatura Infantil e Juvenil a partir da leitura de duas obras literárias, O gato que gostava de cenoura e Sempre por perto. Neste capítulo de Luciano Ferreira da Silva, aborda-se o homoerotismo como desejo 
homoerótico em suas mais diversas manifestações, evitando-se rotulações. Outro estudo, da autoria de Horácio Costa, aborda o homoerotismo nas poesias brasileiras, portuguesa e mexicana do modernismo. Este mesmo autor, em outro capítulo, estabelece as possíveis relações entre o cânone literário e uma conformação estética baseada na experiência e na subjetividade homossexuais, partindo da consideração foucaultiana de que a literatura é fruto do poder disciplinar dos séculos XVIII e XIX, que também incide sobre os dizeres acerca do corpo e do sexo. Assim, traz à baila as contribuições de Antonio Candido, Michel Foucault e da teoria Queer. Marcia Arruda Franco analisa o homoerotismo feminino presente em uma composição trovadoresca datada do século XV. O espaço das intimidades entre autor e leitor é discutido por Antonio Eduardo de Oliveira em um capítulo sobre a obra de Caio Fernando Abreu, considerado o primeiro autor brasileiro a tratar da aids em suas produções.

A parte III compila seis trabalhos sobre Homocultura e Arte, descrevendo e analisando a presença da homoafetividades em obras de teatro, música, pintura e fotografia. Apresenta-se, por exemplo, El Museo Travestí del Perú, além da discussão sobre o corpo na fotografia de Erwin Olaf. Yann Beauvais discute sobre as temáticas homossexuais no cinema brasileiro, que são consideradas alternativas até os dias de hoje e eram identificadas como resistência nas décadas de 1960 e 1970. O autor discorre sobre a importância do cinema experimental no Brasil e no mundo, trazendo à baila as contribuições de cineastas como Jean Cocteau e Curtis Harrington, que objetivavam formar a figura do homossexual por meio do desejo e da ansiedade. O cinema experimental é concebido pelo autor como um espaço de discussão e de expressão não apenas de desejos, mas também de posicionamentos políticos relacionados às temáticas LGBTT. Tais assuntos são discutidos também no teatro brasileiro a partir das reflexões de Ferdinando Martins. Este autor destaca que as imagens do homem gay no teatro brasileiro contemporâneo remetem a diferentes temporalidades que coexistem em um mesmo campo cultural - aí se situa a principal crítica de Martins: de que o espectro de personagens homossexuais existentes indica uma "precariedade da categoria gay para nominar sujeitos coletivos ou identidades genéricas" (p. 245).

A parte IV é intitulada Universo Trans e compreende três capítulos que abordam as experiências de travestis e transgêneros. Em um deles, da autoria de Eliane Borges Berutti, apresenta-se um panorama das travestis no Brasil, retomando-se questionamentos tradicionais como: estariam as travestis inventando um novo feminino? Até que ponto as travestis desafiam os sistemas binários de gênero? A autora compila investigações realizadas nas cidades de São Paulo, Salvador e Rio de Janeiro sobre as práticas das travestis no que se refere ao cuidado estético e experiências de saúde. Em outra importante contribuição, Wiliam S. Peres aborda algumas reflexões sobre o modo como as travestis são vistas, tratadas e reconhecidas nos serviços públicos de saúde. Para tanto, o autor lança a proposta de capacitações desses profissionais com a ajuda de travestis ativistas do Movimento
Nacional das Travestis Brasileiras e de estudiosos do tema, a fim de que os profissionais de saúde possam se apropriar de conhecimentos científicos e práticos sobre gênero, desconstruindo preconceitos e estigmatizações que acabam atravessando o universo dos tratamentos de saúde e do cuidado. Defende-se que travestis possam exercer seus direitos assim como homossexuais e heterossexuais, discutindo questões nas áreas de saúde e educação, por exemplo, a fim de "que nenhuma sexualidade ou expressão de gênero torne-se polícia de outra" (p. 318).

A parte final do livro é intitulada Pensar Identidades, apresentando dez capítulos que abordam desde a chamada crise da masculinidade contemporânea até as vicissitudes relacionadas à construção da homoparentalidade em nosso país. Esses capítulos abordam, de modo mais tangencial ou mais central, a atuação de profissionais de saúde e também ligados ao Direito e às políticas públicas em termos dos atendimentos às pessoas LGBTT. Questões emergentes não se referem apenas a como essas pessoas são "vistas" ou "reconhecidas", mas de que modo elas constroem suas identidades, marcadas pelo preconceito e pela discriminação, como no caso da adoção por casais de pessoas do mesmo sexo. Especificamente em termos da atuação do psicólogo, cabe a regulamentação do exercício da profissão, que condena práticas alinhadas ao preconceito e a qualquer discriminação em termos das sexualidades, por meio da resolução n 001/1999 do Conselho Federal de Psicologia (CFP). Embora haja essa regulamentação, ela não se mostra suficiente para coibir práticas abusivas e discriminatórias por parte de psicólogos e também de assistentes sociais, como as relatadas no capítulo de Lindomar Expedito S. Darós sobre a adoção de uma criança por um casal de homossexuais estrangeiros.

Ao pensar as perspectivas da família contemporânea, Roudinesco (2003) nos atenta para o fato de que a heterormatividade favorece leituras únicas do que é família e de que modo a afetividade pode ser expressa. Um dos desafios dos estudos centrados na família seria justamente relativizar essas normas construídas socialmente e que tomam por base apenas os critérios da tradição, da família patriarcal e da capacidade de reprodução. O desafio de compreender que as famílias ou os arranjos familiares não são estanques é ainda premente, embora essa mudança signifique que as ciências humanas ainda devem reconhecer outros espaços e caminhos para a manifestação do desejo e da família. Obviamente, isso requer a necessidade de um olhar sempre atento, destituído de preconceitos e que desconstrua posicionamentos engessados e que favorecem um discurso único sobre as sexualidades. Ao evocar os diálogos entre arte, literatura e direitos humanos, a obra Retratos do Brasil homossexual cumpre muito mais do que retratar uma realidade ou tornar visíveis os movimentos em torno da constituição das identidades de lésbicas, gays, bissexuais, transexuais e transgêneros - aproxima práticas, reflexões e inquietações necessárias a um fazer profissional e social comprometido com as transformações da sociedade, da academia e dos movimentos identitários. 


\section{Referências}

Conselho Federal de Psicologia (1999). Resolução CFP No. $001 / 99$ de 22 de março de 1999 - Estabelece normas de atuação para os psicólogos em relação à questão da Orientação Sexual. Recuperado em 5 de julho de 2011 de http://pol.org.br/legislacao/pdf/resolucao1999_1.pdf.

Instituto Brasileiro de Geografia e Estatística (2011). Censo contabiliza 60 mil casais gays; metade mora no Sudeste. Recuperado em 29 de abril de 2011 de http://noticias.uol. com.br/ultnot/multi/?hashId=censo-contabiliza-60-milcasais-gays-metade-mora-no-sudeste-0402CC9C3772C C911326\&mediaId=11239793.

Prado, M. A. M., \& Machado, F. V. (2008). Preconceito contra homossexualidades: A hierarquia da invisibilidade. São Paulo: Cortez.

Roudinesco, E. (2003). A família em desordem (A. Telles, Trad.). Rio de Janeiro: Jorge Zahar.

Tomazela, J. M. (2011). Casal gay de SP adota 5 irmãos. $O$ Estado de São Paulo. Recuperado em 5 de julho de 2011, de http://www.estadao.com.br/estadaodehoje/20110702/ not_imp739749,0.php.

Fabio Scorsolini-Comin é Professor do Departamento de Psicologia do Desenvolvimento, da Educação e do Trabalho da Universidade Federal do Triângulo Mineiro.

Recebido: 13/07/2011

$1^{a}$ revisão: $15 / 07 / 2011$

Aceite final: 29/08/2011 